\title{
PESQUISA EXPLORATÓRIA EM DESIGN DE SERVIÇO NUM AMBIENTE HOSPITALAR
}

\author{
Carolina Pizatto \\ Universidade Federal do Paraná \\ carolinapizatto@gmail.com \\ Ricardo Alexandre Leite Martins \\ Universidade Federal do Paraná \\ ricardomartins@ufpr.br
}

Resumo: Este estudo foi baseado no Hospital do Idoso Zilda Arns (HIZA), localizado em Curitiba, no Paraná. Foi realizado com objetivo de definir as expectativas e necessidades de seus usuários acerca do serviço de atendimento prestado. Para o processo de pesquisa, os agentes envolvidos foram submetidos à aplicação de dez ferramentas de Design de Serviço, detalhadas ao longo do documento. Seus resultados determinaram quais são os requisitos que devem subsidiar o novo serviço. A análise destas ferramentas aponta que os usuários estão bastante inseguros quanto ao processo de atendimento do hospital, o que ocasiona ansiedade frente ao serviço. Portanto, a solução proposta deve minimizar esses sentimentos por meio da informação e do engajemento emocional. Em suma, este estudo possibilitou detectar pontos de melhoria no serviço de atendimento prestado bem como comportamentos e práticas comuns ao público idoso no âmbito hospitalar.

Palavras-chave: design de serviço, pesquisa exploratória, serviço de saúde, hospital para idosos

\begin{abstract}
This study was based on Zilda Arns Elderly Hospital (HIZA), which is located in Curitiba, Brazil. It was aimed to define the expectations and needs of its users concerning the healthcare customer service. For the research process, ten Service Design tools were applied to hospital patients. The results defined requirements to orientate the conception of the new service. The analysis of collected data revealed that users are very insecure about the hospital's customer attention, which leads to anxiety towards HIZA's healthcare service as a whole. Therefore, the proposed solution has to minimize these feelings through information and emotional engagement. As a result, this research identified improvement points on the hospital's customer service as well as common behaviors of elderly users regarding hospital service.
\end{abstract}

Keywords: service design, exploratory research, in-depth research, helthcare service, elderly hospital. 


\section{INTRODUÇÃO}

O SUS é um dos maiores sistemas públicos de saúde do mundo. Em 2013, 80\% da população brasileira dependia exclusivamente deste sistema como única forma de acesso à saúde (GAZETA DO POVO, 2013). Contudo, são constantes as reclamações na mídia acerca do serviço prestado pelo SUS. Unidades básicas, postos de prontoatendimento e hospitais da rede pública são alvos das insatisfações. De acordo com o Índice de Desempenho do SUS (IDSUS) de 2012, somente 1,9\% da população vive nos 347 municípios cujos serviços públicos de saúde têm notas acima de 7 (G1, 2013). Ainda assim, para a economia brasileira, o aperfeiçoamento do SUS representa menos de $1 \%$ do plano orçamentário do Governo Federal (CGU, 2015). Além da questão financeira, um dos maiores gargalos é a dificuldade no atendimento, causada, dentre outras fatores, pela falta de apoio adequado ao serviço $(G 1,2014)$.

Fato é que o Brasil ainda caminha a passos curtos no que se refere a um atendimento qualificado a sua população (PORTAL BRASIL, 2012). Nesse sentido, os erros médicos se tornam conseqüência. Ao contrário do que se pensa, estes não são de responsabilidade apenas dos profissionais de saúde. Todo o ambiente onde eles trabalham também influencia no bom ou no mau atendimento ao paciente. Portanto, criar condições que visem a qualificação do atendimento de saúde à população é essencial para reduzir a incidência de erros médicos e melhorar o serviço na rede pública como um todo.

Diante deste contexto, a pesquisa exploratória foi utilizada nesse estudo para coletar expectativas e necessidades do usuário acerca do serviço ofertado a fim de aprimorar $o$ atual atendimento.

\section{MÉTODO DE PESQUISA}

De acordo com Martins \& Merino (2011), para que as aplicações do design sejam feitas de forma adequada, é necessário que se estabelecessem parâmetros do processo que o envolve - ao que se chama metodologia do projeto.

Considerando que o Design de Serviço possui foco no usuário e o considera cocriador de valor (EVERSON, 2008; MAGER, 2008; MORITZ, 2005) o processo construído precisaria envolver os usuários durante suas principais fases.

Na metodologia desenvolvida, a pesquisa exploratória está contida logo após a fase zero, conforme ilustra a Figura 1. 


\begin{tabular}{|c|c|c|}
\hline $\begin{array}{l}\text { FASE } \\
\text { ZERO }\end{array}$ & intent & $\begin{array}{l}0.1 \text { delimitação da proposta } \\
0.2 \text { escoliha da metodologia } \\
0.3 \text { fundarnentaçâao teórica + estudo das ferramentas }\end{array}$ \\
\hline $\begin{array}{l}\text { FASE } \\
\text { EXPLORATÓRIA }\end{array}$ & $\begin{array}{l}\text { know people } \\
\text { know context }\end{array}$ & $\begin{array}{l}\text { 1.1 pesquisa de campo } \rightarrow \text { levantamento de dados laplicaçåo das ferramentas] } \\
1.2 \text { pesquisa de similares }\end{array}$ \\
\hline $\begin{array}{l}\text { FASE } \\
\text { SINTESE }\end{array}$ & frame insights & 2.1 análise dos dados coletados $\rightarrow$ diretrizes para conceito \\
\hline $\begin{array}{l}\text { FASE } \\
\text { DESENVOLVMENTO }\end{array}$ & $\begin{array}{l}\text { frame concept } \\
\text { frame solutions }\end{array}$ & $\begin{array}{l}3.1 \text { criaç̧a de conceito } \\
3.2 \text { workshops de co-criaçăo } \rightarrow \text { geraçăo de alternativas } \\
3.3 \text { plano de açăo } \\
3.4 \text { proposta final } \rightarrow \text { soluçåo recomendada } \\
3.5 \text { projeto graffico }\end{array}$ \\
\hline \multicolumn{3}{|l|}{ ENTREGA } \\
\hline $\begin{array}{l}\text { FASE } \\
\text { IMPLEMENTAÇĀO }\end{array}$ & reatize offerings & $\begin{array}{l}4.1 \text { validaçâa } \rightarrow \text { prototipaçào } \\
4.2 \text { ajustes } \\
4.3 \text { aplicaçăo do plano de açăo } \\
4.4 \text { gerenciamento e acompanhamento da mudança }\end{array}$ \\
\hline $\begin{array}{l}\text { FASE } \\
\text { FEEDBACK }\end{array}$ & & $\begin{array}{l}5.1 \text { avaliar implementaçăo } \\
5.2 \text { identificar aprendizado * oportunidades de methoria }\end{array}$ \\
\hline
\end{tabular}

Figura 1 - Processo de design.

Fonte: Elaborado pelo autor, com base na pesquisa realizada.

Apesar de também ser composta pela pesquisa de similares, a fase exploratória enfatizou a pesquisa de campo. Esta foi responsável por ampliar o espaço problema do projeto, através dos dados coletados via observação ou interação com usuários.

No início do projeto procedeu-se à escolha dos objetivos, da fonte de dados, do método de pesquisa e da amostragem. A coleta de dados foi feita em seguida.

\subsection{Objetivos principais e secundários}

O objetivo principal da pesquisa foi encontrar dados para subsidiar um projeto de Design de Serviço para o atendimento do HIZA.

Os objetivos secundários foram:

(1) Obter a planta do hospital e delimitar a zona de coleta de dados;

(2) Coletar dados demográficos, psicográficos e comportamentais do usuário;

(3) Determinar variáveis iniciais para a construção de personas, em conjunto com os dados documentais providos pelo hospital;

(4) Descobrir as dificuldades que os usuários encontram enquanto submetidos ao serviço de atendimento no HIZA;

(5) Compreender o nível de satisfação dos usuários acerca do serviço prestado pelo HIZA;

(6) Identificar requisitos que os usuários julgam como básicos para uma boa perfomance de atendimento na área da saúde.

\subsection{Amostragem}

A amostragem para aplicação dessas ferramentas foram os agentes diretamente envolvidos no serviço de atendimento do HIZA, como pacientes, acompanhantes e funcionários do hospital. A técnica amostral é não-probabilística por acaso único, obtida por conveniência. Ao todo, 85 pessoas foram envolvidas.

As pesquisas foram feitas durante os meses de Julho e Agosto de 2015, com preferência para as terças e quintas-feiras, por serem dias com maior movimento, em 
horários aleatórios entre $7 \mathrm{~h} 30$ e 18h. Sua abrangência restringiu-se ao HIZA, envolvendo participantes de várias regiões de Curitiba.

\subsection{Ferramentas escolhidas}

A pesquisa envolveu dez ferramentas de Design de Serviço. Elas foram utilizadas para coletar, compilar e traduzir dados do estudo exploratório; e viabilizaram a imersão em profundidade, permitindo uma visão sistêmica do hospital.

Foram utilizadas as ferramentas: Mapa do Sistema, Observação Etnográfica, Personas, Entrevistas, Storyboard, Emotional Wheel, Shadowing, Servqual, Grupo Focal e Análise da Ouvidoria, as quais são detalhadas a seguir.

\subsubsection{Mapa do Sistema}

Para melhor situar o HIZA dentro do sistema no qual ele está inserido, e entender quem são e onde estão os demais stakeholders desse processo, o Mapa de Sistema foi utilizado.

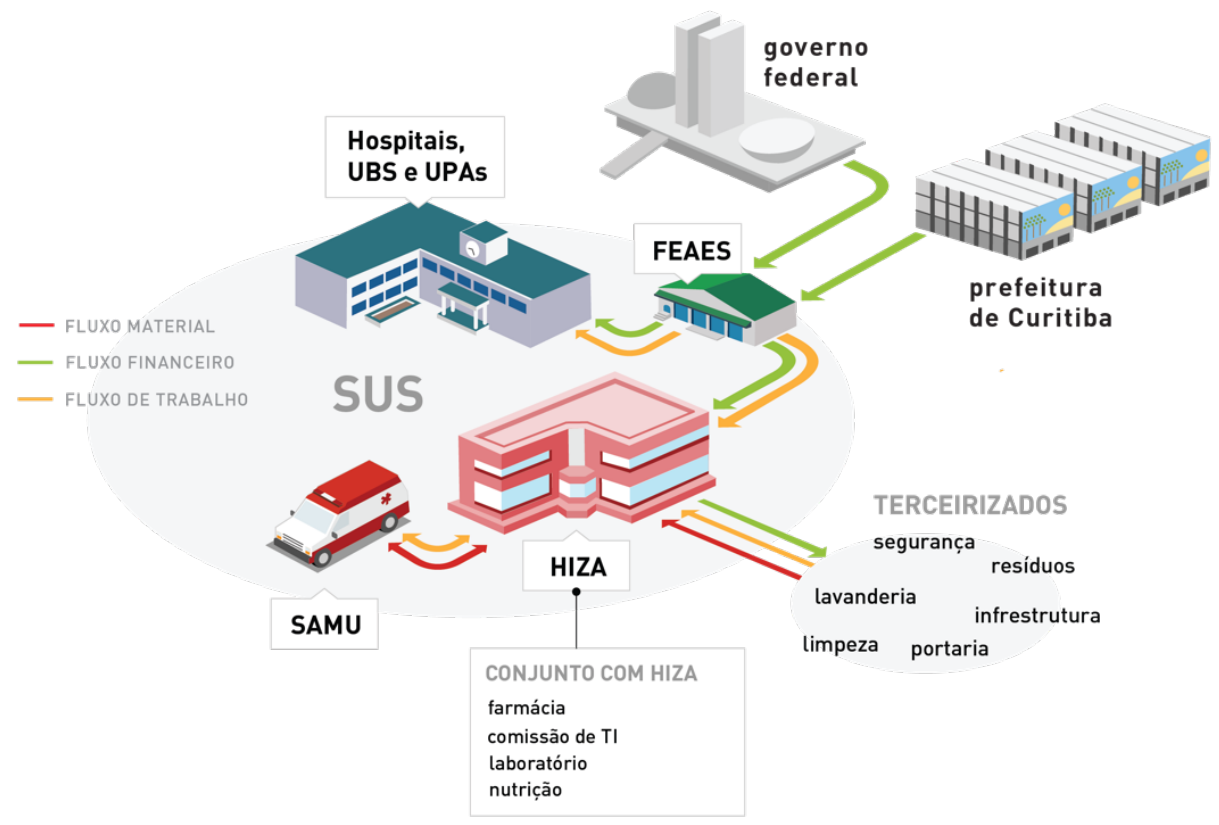

Figura 2 - Mapa do sistema.

Fonte: Elaborado pelo autor, adaptado de Santos (2014).

\subsubsection{Observação Etnográfica}

Em paralelo, a técnica de observação direta foi aplicada no HIZA com o objetivo de identificar parâmetros iniciais para planejar as etapas da coleta de dados. Uma ficha foi construída como suporte de investigação. As informações foram tabuladas para posterior análise. Mas esta ferramenta não foi suficiente para identificar o fluxo dos atendimentos, seu volume, sua sazonalidade, suas patologias, e a idade dos usuários. Estes dados secundários foram concedidos pelo próprio HIZA.

\subsubsection{Personas}

Essa técnica serviu para a caracterização dos usuários, usando tabelas enviadas pelo HIZA. Elas dividem os pacientes em 4 nichos: internação; emergências; ambulatório e externo. Com base no perfil dos usuários, o setor de consultas e 
externo, representado pelos exames, foram escolhidos para a fase exploratória. Gerou-se 3 personas para este trabalho, que orientaram as etapas conseguintes.

A área delimitada por estes atendimentos foi destacada na Figura 3.

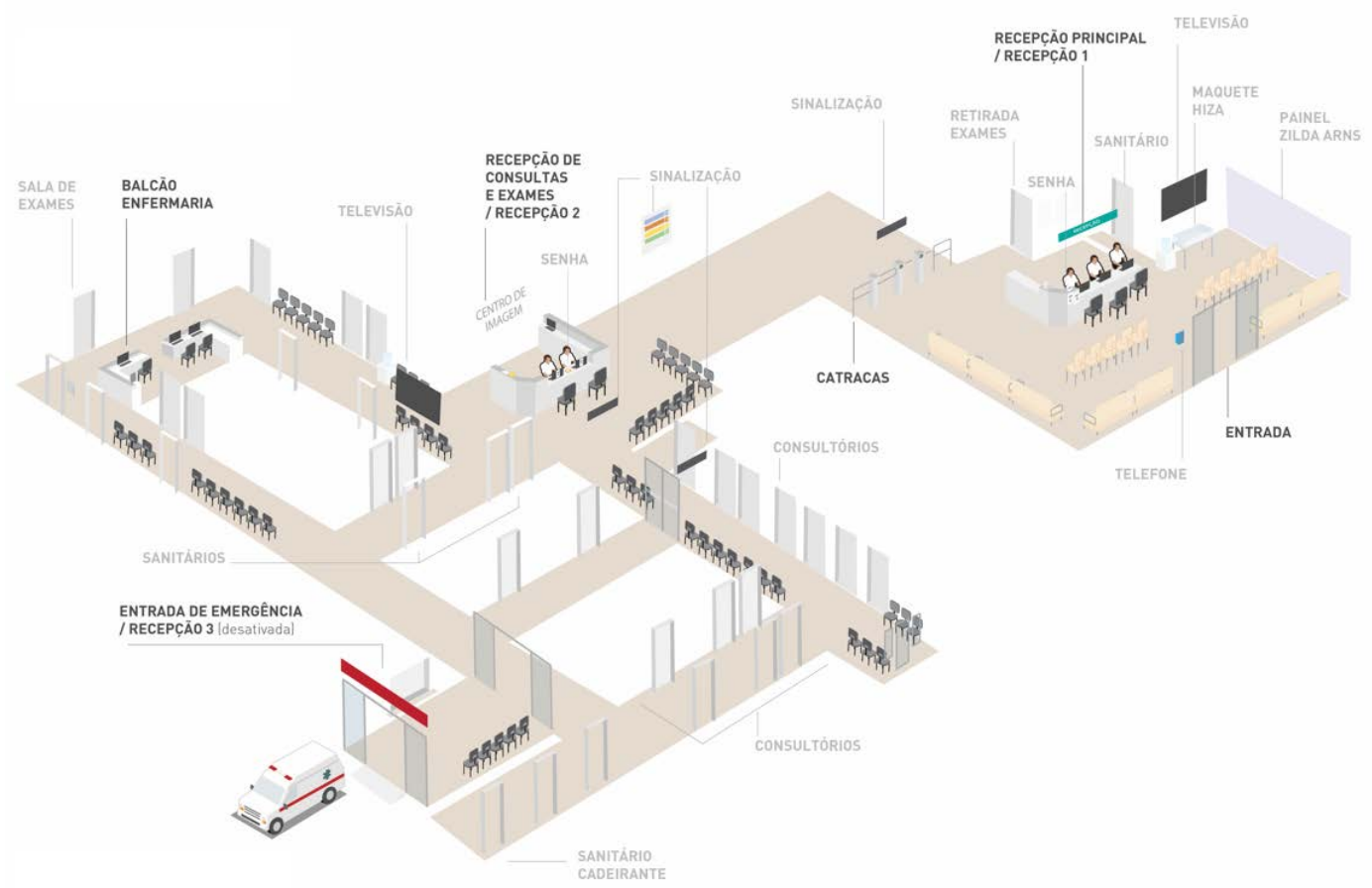

Figura 3 - Representação da área de consultas e exames do HIZA.

Fonte: Elaborado pelo autor, com base na pesquisa realizada.

\subsubsection{Entrevistas}

A partir desse momento começaram as interações com os usuários principais do hospital. Foram feitas entrevistas, pessoalmente, em dois momentos: antes e depois do atendimento.

A entrevista inicial (antes do atendimento) serviu para aprofundar e detalhar o perfil dos usuários do serviço. Logo, as perguntas se relacionavam ao sexo, profissão, moradia, frequência e motivo da visita, por exemplo. Também foram pedidas contribuições dos usuários sobre o serviço de atendimento do HIZA. A segunda entrevista, final (após o atendimento) buscava descobrir quais as percepções dos usuários acerca do serviço de atendimento recebido.

Para garantir a efetividade da pesquisa elaborada, um piloto foi executado com uma amostra de 7 participantes, sendo 4 referentes à entrevista inicial e 3 à final. 0 piloto identificou pequenos erros no questionário da entrevista inicial. Além dos ajustes de redação, a entrevista final também passou a contar com a aplicação de duas outras ferramentas: Storyboard e Emotional Wheel.

Depois de realizadas, todas as entrevistas levantaram pontos de atenção, como a recepção de consulta e exames, o estacionamento, a catraca e o sistema de remarcação de agendamentos.

\subsubsection{Storyboard}

Para facilitar a interação com os usuários, um Storyboard da jornada percorrida no HIZA foi criado para auxiliar a aplicação da entrevista final. Visto que cada usuário poderia apresentar uma jornada diferente, cartas separadas foram elaboradas para 
compor o Storyboard. Assim, a sequência de imagens da jornada era adaptável a cada situação.

Mesmo assim, para fins de documentação, números foram incluídos em cada carta. Estes, porém, não necessariamente significam a ordem na qual os eventos devem acontecer.

\subsubsection{Emotional Wheel}

Além do Storyboard, também foi utilizada a técnica Emotional Wheel. Ela revela quais são os sentimentos do usuário em cada etapa do atendimento. Para sua aplicação, uma tira de papel com várias expressões faciais foi desenvolvida.

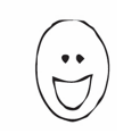

Animado

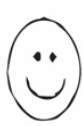

Feliz

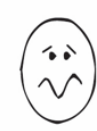

Angustiado

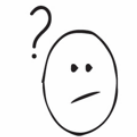

Com Dúvida

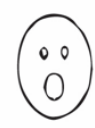

Assustado

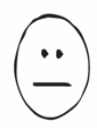

Apático

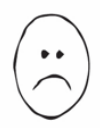

Triste

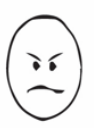

Nervoso

Figura 4 - Expressões faciais para o Emotional Wheel.

Fonte: Elaborado pelo autor, com base na pesquisa realizada.

Diante dos rostos representados, os pacientes foram orientados a indicar o que sentiam em cada uma das etapas do atendimento, com o auxílio visual do Storyboard.

Os dados obtidos revelaram que o sentimento "feliz" está presente em praticamente todo o percurso. Os dados também foram classificados em positivos ou negativos (+) e (-). A tabela revela que a maioria dos sentimentos foram positivos.

\begin{tabular}{|c|c|c|c|c|c|c|c|c|}
\hline nesteravent & Entrade & $2^{2}$ hecensas 1 & Evera Aecess ba & EMraca & 5 & $\begin{array}{l}\text { Esouse Recento } \\
z\end{array}$ & $\begin{array}{l}\text { Espers } \\
\text { Corsultire/tume }\end{array}$ & Censcán \\
\hline Eiane & Ielis & Fotit & Feliu & Com Dovise & Felit & . & Angustids & Ansubitial \\
\hline Pursing & Animuds & Foliz & $=$ & Feliz & + & Com Dovita & Foida & Animado \\
\hline Neti & 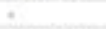 & Feliz & Felu & Feliz & Felit & Felit & Apitica & Animato \\
\hline Avgelits & Acsustala & Felliz & Cens Dovids & Felle & $=$ & . & Anyutiods & Animato \\
\hline Hupo Jerye & Animuso & Fetir & Cem Dinde & Cein Owiste & Feliz & . & Anyatiode & Arimate \\
\hline Ide & Anevatiode & Meguriasto & Angustiage & Com Durits & . & . & Aptefes & Arimats \\
\hline Nevisa & Animads & Fetiz & Felis & Com Dovita & Fetiz & . & Felia & $F_{e s t}$ \\
\hline Terens & Animads & . & Felit & Feliz & Felit & . & Feid & Animato \\
\hline Vaimer & Feliu & Fetie & $=$ & Apatice & Aotice & . & $=$ & 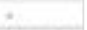 \\
\hline Roterts & Felik & Felit & . & Feliz & $\cdot$ & Animass & Aplices & Arimads \\
\hline Iriney & 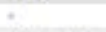 & 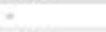 & . & $=$ & Animado & 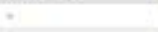 & Fele & $=$ \\
\hline Leener & Assvatasa & Feliz & . & Feliz & Com Dovida & . & Animado & Feliz \\
\hline Artan & Animuss & Foliz & Felus & Animute & Feliz & $=$ & 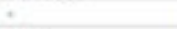 & $=$ \\
\hline Joseitha & Felis & Fetiz & Fellie & Fetiz & . & . & Thuse & Fease \\
\hline lesura & Feliy & Acimade &. & Cem Dovise & Animade & . & Feis & Felis \\
\hline
\end{tabular}

Tabela 1 - Sentimentos do Emotional Wheel.

Fonte: Elaborado pelo autor, com base na pesquisa realizada.

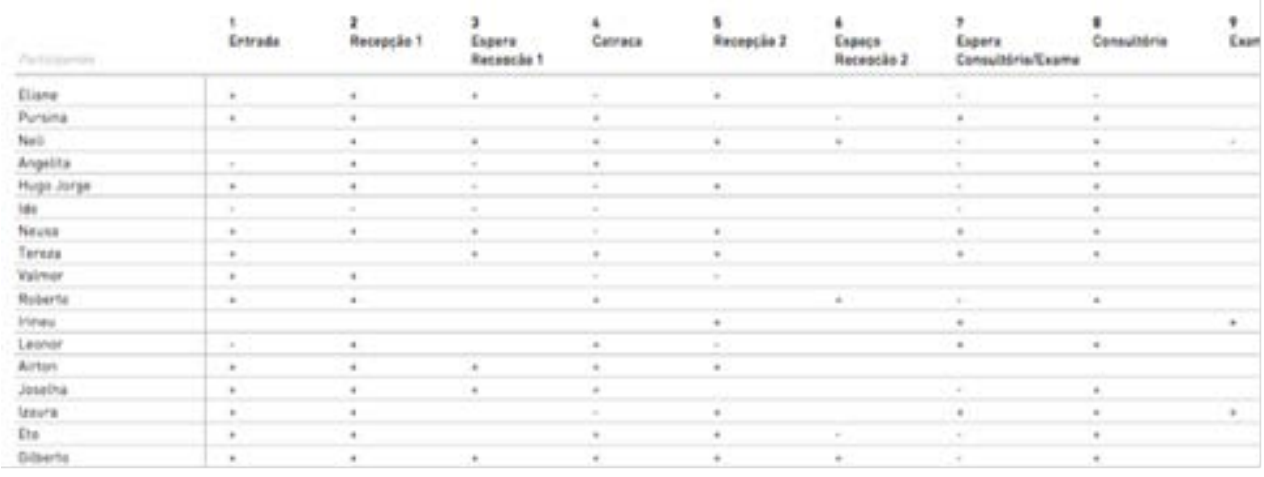

Tabela 2 - Conotação dos sentimentos do Emotional Wheel.

Fonte: Elaborado pelo autor, com base na pesquisa realizada. 
Com a aplicação do Emotional Wheel, encerrou-se o processo da entrevista final.

\subsubsection{Shadowing}

Essa ferramenta permitiu detalhar melhor o percurso do usuário. O Shadowing foi realizada com 10 pacientes e registrado por anotações. Ao final, os pacientes eram submetidos à entrevista final. Os dados alimentaram as fichas de documentação, com citações, tempos e erros padrões. Esta atividade revelou problemas recorrentes na entrada de emergência e na recepção de consulta e exames. Também mostrou pontos de fraqueza do serviço na retirada da senha na recepção principal e na passagem pela catraca, que é dificultada caso o porteiro não esteja ali.

\subsubsection{Servqual}

Para avaliar a qualidade do atendimento nas consultas e exames do HIZA, foi utilizada a pesquisa Servqual, que é uma survey que investiga qual a percepção dos pacientes sobre 12 aspectos da qualidade e seus respectivos pesos. Esses fatores são divididos em 5 grupos (PARASSURAMAN ET AL., 1995), conforme visto a seguir:

\section{Tangibilidade}

Estrutura física, limpeza, beleza e conforto do Hospital; Equipamentos modernos no Hospital; Profissionais bonitos e bem arrumados

\section{Credibilidade}

Diagnósticos corretos; Prazo e Pontualidade; Relação serviço recebido VS. impostos pagos

\section{Presteza}

Rapidez no atendimento; Facilidade em ser atendido;

\section{Segurança}

Médicos competentes e confiáveis; Ambiente seguro

\section{Empatia}

Equipe paciente, carinhosa e atenciosa; Atendimento individualizado

A pesquisa foi aplicada ao final do atendimento, visto que cada paciente necessitava ter a percepção de serviço recebido, para então poder efetuar a comparação com suas expectativas.

Durante a entrevista com os pacientes pediu-se que ele indicasse qual era o grau de importância para cada um dos cinco tópicos, em uma escala de -3 (péssimo) a 3 (excelente). Na sequência, cabia ao paciente revelar seu nível de percepção, sob a mesma escala, após o atendimento no HIZA.

Assim como as demais ferramentas, as avaliações coletadas foram transpassadas para uma tabela. Através dela, percebe-se que as maiores lacunas estão nos aspectos de: equipamentos modernos no hospital, diagnósticos corretos, relação serviço recebido vs. impostos pagos, rapidez no atendimento, facilidade em ser atendido, e médicos competentes e confiáveis. Neste ponto, com exceção dos atributos de rapidez no atendimento, a maioria dos dados coletados pelo Servqual foram novos ao projeto.

\subsubsection{Grupo Focal}

O grupo focal neste estudo serviu para entender algumas dúvidas que surgiram na pesquisa, como a percepção geral sobre o HIZA. Também foi útil para aprofundar o entendimento das insatisfações apontadas pela pesquisa Servqual.

Houveram 8 participantes, divididos em 3 grupos: pacientes, composto por 2 pacientes internados e 1 paciente de exame; acompanhantes, na figura de 1 
acompanhante; e especialistas, com 1 médico, 1 enfermeira, 1 atendente da recepção principal, e 1 atendente da recepção de exames e consultas.

Neste caso, o objetivo de unir características heterogêneas foi utilizado principalmente a fim de integrar a figura do médico, enfermeiro e funcionário ao processo de investigação em campo, bem como gerar maior discussão acerca dos interesses e percepções individuais de cada nicho participante.

Um roteiro foi criado para a realização do grupo focal. A atividade de Cardsorting foi adicionada à estrutura como parte da interpretação sobre equipamentos modernos, para acompanhar algumas perguntas específicas, a fim de revelar visualmente qual é o nível de tecnologia desejado pelos envolvidos neste serviço.

Mas antes, um piloto do grupo focal foi aplicado. Com ele, questões pertinentes ao moderador e a atividade com cartas foram ajustadas. O grupo focal final foi realizado em uma sala dentro do próprio complexo do HIZA e durou 1 hora e 30 minutos.

Como resultado, percebeu-se uma tendência maior para os comentários gerados por especialistas. Mesmo assim, problemas já apresentados por meio de outras ferramentas, principalmente pela Etnografia, foram reforçados. Casos como o da confusão dos pacientes na recepção de exames e consultas, a dificuldade dos pacientes que visitam o HIZA pela primeira vez, a dificuldade de retirar senha em ambas as recepções, a falta de informação visual para orientar os pacientes, e a dificuldade para embarque e desembarque, principalmente com relação ao cadeirante, foram levantados.

As perguntas específicas, por sua vez, trouxeram contribuições mais efetivas. Com elas, descobriu-se que a tecnologia é fundamental, porém não deve ser substituída pelo carinho ao paciente. Ou seja, a prioridade levantada pela Serqual se confirmou. Contudo, vale lembrar que, nesta mesma ferramenta, a lacuna referente ao carinho do atendimento HIZA foi pequena. Com relação à diagnósticos corretos, os dados levantados pelo grupo focal foram contraditórios ao Servqual. Para os presentes, o HIZA é referência em diagnósticos corretos. Sobre rapidez de atendimento, um descobrimento é válido de ser comentado. Por mais que as entrevistas indicaram que o serviço de atendimento prestado pelo hospital é rápido, o grupo focal revelou que os idosos não gostam de esperar. Além deles, os acompanhantes também não têm tempo a perder.

\subsubsection{Ouvidoria}

Dados secundários da Ouvidoria do HIZA também foram analisados. As fichas da Ouvidoria ficam dispostas na recepção principal do hospital e podem ser preenchidas por qualquer pessoa que por ali passa. Após respondidas, são armazenadas na urna ao lado e compiladas mensalmente em uma tabela, pelos responsáveis administrativos.

Para esta análise, apenas os dados relevantes ao serviço de atendimento foram extraídos das fichas de avaliação. Estas informações correspondem as perguntas 2 (atendimento da recepção principal), 4 (atendimento do médico), 10 (atendimento do hospital) e 12 (recomendação do hospital). As notas recebidas pelo HIZA desde o começo de 2015 para estes quesitos foram organizadas numa tabela.

Percebe-se que as avaliações feitas por este instrumento são extremamente positivas. Ainda assim, as perguntas 2 e 10 são as que apresentam maiores médias de notas "Muito Bom". Ou seja, seus índices "Excelente" não são os maiores possíveis, demostrando oportunidade de melhoria. Independentemente, por ser um instrumento 
de medição simples e de forte caráter quantitativo, pouca é sua relevância nesta pesquisa.

\section{RESULTADOS}

A pesquisa de campo atingiu seu objetivo principal e secundário pois permitiu traçar os principais passos percorridos pelos pacientes que usufruem dos serviços de atendimento para consultas e exames no Hospital do Idoso Zilda Arns.

Com o propósito de entender quais foram os problemas encontrados durante as fases anteriores, as informações coletadas foram organizadas de acordo com o momento da jornada do usuário a qual elas pertencem.

Os principais problemas apontados sobre a entrada no hospital foram: o tamanho do estacionamento, a falta de um acesso a cadeirantes e o não funcionamento da recepção de emergência. Nestes itens, as contribuições sugerem a reativação desta recepção, para melhorar o acesso daqueles que adentram via ambulância, a criação de um espaço de embarque/desembarque, e o aumento do estacionamento.

Já na área referente à recepção principal, os principais achados demonstram insatisfação com o sistema de retirada e chamada das senhas, e a falta de materiais como copos descartáveis e álcool gel, por exemplo. Os insights dos usuários sugerem a necessidade da inserção de painéis eletrônicos e melhor sinalização para a retirada das senhas. Ademais, também foram dadas sugestões para a separação entre o balcão de atendimento, e um possível novo balcão exclusivo para recepcionar, direcionar e oferecer informações aos usuários do HIZA - funcionando como uma espécie de prétriagem ao serviço de atendimento. Além disso, a possibilidade de um som relaxante também foi comentada. Nesse aspecto, a decoração e temperatura do ambiente poderiam ser ajustadas.

Ainda na recepção principal, a sala para retirada de exames não está bem localizada. Por mais que não seja necessário a retirada de senha e o consequente atendimento para acessá-la, isto é o que a maioria dos usuários faz, acarretando esperas e fluxos desnecessários.

A passagem pela catraca também constitui um problema. Apesar de ser considerada um bom ponto de contato entre hospital e paciente, por promover interação e representar atenção e carinho, a figura do porteiro poderia ser repensada. O trabalho, aliás, é estressante sobre o ponto de vista dos próprios funcionários. Entretanto, mesmo não sendo considerada complexa pelos usuários, estes demonstram dificuldade em utilizar a catraca sem nenhuma forma de auxílio. No geral, a percepção dos pacientes é de que o erro é deles, ou seja, o problema não é a catraca, mas sim do usuário. Contudo, sabe-se que este entendimento não é correto.

Passado este momento, a indecisão sobre qual rumo tomar dentro do hospital é recorrente, mesmo incluindo o fato de que as atendentes da recepção principal são instruídas a orientar todos os usuários sobre quais orientações estes devem seguir. A placa de sinalização que encontra-se entre os corredores de internação e consultas e exames é pouco acessada. Os fatores que justificam este hábito estão alocados nas justificativas de que independente da orientação visual, os idosos sentem a necessidade de reforçarem via comunicação verbal. Isto porque os idosos são carentes, gostam de interagir e precisam ter a informação repetidas vezes, por diferentes formas, para que consigam armazená-la. Cabe comentar que apesar desta 
desorientação ser mais frequente e profunda em novos usuários, pacientes recorrentes também são afetados. A inserção de uma terceira forma de orientação, a qual considera que os idosos rotineiramente olham para o chão enquanto caminham, sugere a aplicação de uma sinalização no piso.

A passagem pela recepção de consulta e exames é um dos pontos mais críticos do serviço de atendimento ofertado pelo HIZA. O principal problema relacionado ao espaço reside na dúvida dos usuários em parar, ou não, no balcão de atendimento entitulado de "Centro de Imagem e Som". Ainda que sendo instruído para seguir direto a sala de espera dos consultórios e exames, a esmagadora maioria dos usuários não só param, como inclusive retiram senha e aguardam atendimento em uma parada que não é sequer necessária. Em tese, pacientes só são instruídos a solicitar atendimento neste balcão em casos de exames como eletrocardiogramas, por exemplo, que podem ser realizados pré-consulta médica. Este procedimento, porém, também é orientado pelos atendentes da recepção principal. Nos demais, este espaço é de uso exclusivo para remarcação de consultas médicas e agendamentos de exames solicitados durante a consulta médica. A dificuldade de encontrar os consultórios médicos e as salas de exame também foi comentada, ainda que em menor escala.

Quanto aos consultórios, em especial, a dúvida não é somente onde eles estão mas principalmente qual é o médico que nele está atendendo, visto que estes podem trocar seus espaços de trabalho conforme disponibilidade. A insegurança causada pela falta de informação quanto à sala do médico faz com que o paciente muitas vezes recorram aos atendentes da recepção de consulta e exames, os quais atuam como informantes e orientadores, ao invés de executar seu trabalho propriamente dito. Com base neste contexto e considerando que os médicos também chamam seus pacientes somente através da voz, a mesma sugestão de painel eletrônico dada à recepção principal também foi adicionada a esta parte da jornada. Esta tecnologia, por sinal, já está implantada como padrão nas Unidades de Saúde Básica e Pronto-Atendimento de Curitiba.

O momento no qual o paciente aguarda pela sua consulta médica ou exame também é marcado por alguns problemas. O principal diz respeito ao tamanho do espaço destinado à espera. $O$ ambiente ao entorno da recepção de consulta e exames é o que comporta o maior fluxo do HIZA, que vai desde macas de emergência e transporte de equipamentos de exame, até serviços de coleta de lixo e limpeza. Logo, apesar do hospital possuir um grande complexo, sua seção mais recorrente é a menor em tamanho. Diante dessa situação, a espera, que por si só já não é um ato considerado agradável, torna-se ainda mais complicada, uma vez que o ambiente está cheio, agitado e abafado. Vale ressaltar que a entrada de ar é limitada por apenas 2 janelas basculantes, e nem mesmo o banheiro local possui saída para ventilação.

Além disso, é importante pontuar que este é o segundo momento da jornada de atendimento no qual o paciente precisa aguardar. A primeira, ainda na recepção principal, foi reportada como rápida. Logo, assim que o paciente adentra as catracas e vai em direção aos consultórios, há certa expectativa de que a espera será tão pouca como foi anteriormente. Contudo, ao se defrontar com dificuldades para encontrar o local e aos aspectos do ambiente de espera, a experiência do usuário neste ponto é comprometida. Como sugestão de melhoria, as informações recolhidas apontam o desejo dos usuários por maior entretenimento enquanto na espera. A televisão, por si só, não é suficiente. Além das dificuldades auditivas e visuais apresentadas pelos 
idosos, os corredores das salas de consulta não possuem o equipamento. Comentários como a disponibilização de cestas de fruta e café foram coletados.

A etapa de consulta, por sua vez, não registrou nenhuma crítica. Os médicos foram elogiados pelo bom desempenho, por serem capaz de emitir diagnósticos corretos e por seu carinho frente aos pacientes. Neste aspecto, a relevância do carinho é maior do que a tecnologia utilizada no serviço. O tempo da consulta foi apontada como uma medição para o nível de atenção dada ao paciente. Sendo assim, os médicos precisam ponderar entre cumprir seus horários, atender a todas as consultas e exames diários e, ainda, depreender certo tempo para demonstrar empatia para com o paciente em questão. Apesar de ser positiva do ponto de vista do usuário, esta lógica colabora no aumento do período de espera dos demais pacientes.

Ao final de seu atendimento, os usuários retornam à recepção de consulta e exames para realizar novos agendamentos. Dentre os problemas estão a falta de atenção exclusiva por parte dos funcionários aos pacientes. Isto ocorre visto que os atendentes também precisam dar informações a outros usuários enquanto realizam atendimento. Diante dessa situação, aumenta-se o tempo de espera, e a dificuldade de visibilidade e escuta da senha, assim como acontece na recepção principal. Neste ponto, é preciso lembrar que o usuário já está com certa bagagem emocional acumulada durante todo seu trajeto dentro do hospital, e seus últimos estágios antes da finalização do serviço de atendimento são decisivos para a construção da percepção geral acerca do HIZA.

Contudo, a pesquisa exploratória também revelou certos pontos positivos do HIZA que merecem ser registrados. Sua aparência e estrutura física são frequentemente comparadas a hospitais particulares, e sua reputação é grande no âmbito do cuidado ao idoso - por mais que seus funcionários, médicos e enfermeiros não recebam nenhum treinamento específico acerca dos cuidados necessários com este público. Além disso, destaca-se o atendimento rápido, se comparado com outras unidades do serviço público, como as UPAS e UBS, e a possibilidade de agendamento de horário, mesmo que ainda não via telefone.

Fato é que para resolver as questões levantadas, faz-se necessário investigar qual é a causa raiz para que eles aconteçam. Ou seja, identificar qual é o mal maior que, quando eliminado, irá melhorar o serviço de atendimento do hospital.

Nesse sentido, percebeu-se que os usuários são, de forma geral, bastante inseguros quanto ao processo de atendimento do HIZA. Como consequência, eles também sentem-se ansiosos.

Tendo em vista todo este apanhado, quatro diretrizes foram criadas para orientar a geração do conceito deste projeto:

$>$ Processos carecem de praticidade e agilidade

$>$ Usuários estão desorientados

$>$ Usuários buscam suporte emocional

$>$ Usuários querem conforto

Portanto, o desafio está em criar uma solução de serviço capaz de abranger os pontos expostos acima, e também reduzir a ansiedade e insegurança dos usuários. $O$ novo serviço de atendimento do HIZA deve ser mais prático e ágil, de fácil navegação, oferecer maior engajamento emocional e proporcionar o conforto de seus usuários. 


\section{REFERÊNCIAS}

CONTROLADORIA GERAL DA UNIÃO (CGU). Gastos Diretos por Programa. Portal da Transparência Governo Federal. 2015. Disponível em: http://www. portaltransparencia.gov.br/PortalTransparenciaGDProgramaPesquisaAcao.asp?ano=2014\&codigoProgr ama=2015\&textoPesquisaPrograma=2015.

EVERSON, S. A Designer's View of SSME. In: B. HEFLEY; W.; MURPHY (Eds.); Service Science, Management and Engineering Education for the 21st Century. p.376, 2008. New York: Springer.

G1. De 0 a 10, índice do governo dá nota 5,4 à saúde pública no Brasil. 2012. Disponível em: http://g1.globo.com/ciencia-e-saude/noticia/2012/03/de-0-10-indicedo-governo-da-nota-54-saude-publica-no-brasil.html.

G1. Saúde gasta só $\mathbf{1 0 \%}$ da verba para investimento em 10 anos, diz entidade. 2014. Disponível em: http://g1.globo.com/distrito-federal/noticia/2014/04/saude-gasta-so10-da-verba-para-investimento-em-10-anos-diz-entidade.html

GAZETA DO POVO. Pouco equipado, SUS atende $\mathbf{8 0 \%}$ da demanda. Disponível em: http://www.gazetadopovo.com.br/vida-e-cidadania/pouco-equipado-sus-atende-80da-demanda-c7e43183qbr34izwj6h5hx00e.

MAGER, B. Service design. In: M. Erlhoff; T. Marshall; Design Dictionary: Perspectives on Design Terminology. p.354-357. Birkhäuser Verlag AG. doi: 10.1007/978-3-76438140-0_244, 2008.

MARTINS, Rosane; MERINO, Eugenio. A Gestão do Design como Estratégia Organizacional. Rio de Janeiro: Rio Books, 2011.

MORTIZ, S. Service Design Practical Access to an Evolving Field. 2005. $125 f$.

Dissertação (MA European Studies in Design - Köln International School of Design). London, 2005.

PARASURAMAN, A.; ZEITHAML, V. A.; BERRY, L. L. A conceptual model of service quality and its implications for future research. Journal of Marketing, USA, v.49, n.4, p. 41- 50, 1985.

PORTAL BRASIL. Investimentos em educação e saúde no Brasil estão longe dos padrões internacionais, diz Ipea. 2012. Disponível em:

http://www.brasil.gov.br/educacao/2012/05/investimentos-em-educacao-e-saude-nobrasil-estao-longe-dos-padroes-internacionais-diz-ipea

SANTOS, L. Design de Serviços Front Desk. Apresentação de slides. Trabalho de Graduação (Disciplina de Design de Serviços) - Curso de Design Gráfico, Universidade Federal do Paraná, Curitiba, 2014. 